\title{
Relato de experiência do uso da plataforma Google Classroom no curso de Jornalismo
}

\section{Experience report on the use of the Google Classroom in the undergraduate program in Journalism}

\author{
Isis Nalba Albuquerque Cardoso \\ Universidade Federal de Alagoas
}

\author{
Cleide Jane de Sá Araújo Costa \\ Universidade Federal de Alagoas
}

\section{Fernando Silvio Cavalcante Pimentel}

Universidade Federal de Alagoas

\begin{abstract}
Resumo: $O$ artigo descreve a experiência de utilização da plataforma Google Classroom como Ambiente Virtual de Aprendizagem (AVA) com alunos da disciplina de oficina de produção audiovisual, ofertada nas turmas I (2018.2) e turma II (2019.1), no turno noturno do curso de graduação em Jornalismo da Universidade Federal de Alagoas (UFAL). Trata-se de um trabalho qualitativo-descritivo, cujos objetivos foram aprofundar os conhecimentos acerca do cinema e audiovisual, complementar as aulas presenciais, além de otimizar o tempo e o interesse dos alunos nas aulas. Conteúdos voltados ao audiovisual, com foco para o cinema e, em especial, as produções alagoanas, foram trabalhados por meio de vídeos, textos, quiz, além das exposições e debates presenciais. Todas as postagens e interações no ambiente virtual foram avaliados de forma individual e contínua. Os resultados mostraram que o uso da plataforma foi efetivo e contribuiu para a maior participação e interesse dos discentes.
\end{abstract}

Palavras-chave: Educação. Google Classroom. Ambiente virtual de aprendizagem. Jornalismo. Cinema.

\begin{abstract}
The paper describes the experience of using the Google Classroom platform as a Virtual Learning Environment with students of the course of audiovisual production workshop, offered in classes I (2018.2) and class II (2019.1), in the night shift of the undergraduate program in Journalism at the Federal University of Alagoas. It is a descriptive qualitative study, whose objectives were to deepen the knowledge about cinema and audiovisual media, complement the face-to-face classes, and to optimize students 'time and interest in classes. Contents focused on audiovisuals, with a focus on cinema and, in particular, productions made in Alagoas, were worked on through videos, texts, quizzes, as well as face-to-face exhibitions and debates. All posts and interactions in the virtual environment were evaluated individually and continuously. The results showed that the use of the platform was effective and contributed to the greater participation and interest of the students.
\end{abstract}

Keywords: Education. Google Classroom. Virtual learning environment. Journalism. Cinema. 
CARDOSO, Isis Nalba Albuquerque; COSTA, Cleide Jane de Sá Araújo; PIMENTEL, Fernando Silvio Cavalcante. Relato de experiência do uso da plataforma Google Classroom no curso de Jornalismo. Informática na Educação: teoria \& prática, Porto Alegre, v. 23, n. 3, p. 118-131, set./dez. 2020.

\section{Introdução}

Com o objetivo de estruturar teoria, técnica, ética e pesquisa, além da prática profissional de excelência, contribuindo para a qualificação do setor de comunicação em Alagoas, o curso de Jornalismo da Universidade Federal de Alagoas (UFAL) foi criado em 1978 e, desde então, forma profissionais para atuar no mercado e cumprir seu papel na sociedade. Todavia, as modificações sociais pautadas pelas Tecnologias Digitais da Informação e Comunicação (TDIC), pelo crescimento do ciberespaço e pelo desenvolvimento do que Lévy (1999) denomina de cibercultura, supõem mudanças também na profissão de jornalista que, alinhada à sociedade contemporânea, está cada vez mais pautada pelo uso das TDIC. Machado (2003) explica que a tecnologia pressupõe o desenvolvimento do jornalismo digital que, segundo o autor, está diretamente relacionado aos limites do ciberespaço. Já Silva (2008) aponta para o uso das tecnologias móveis na produção jornalística. Para o autor, com o auxílio do smartphone, por exemplo, o jornalista pode produzir, editar e publicar imediatamente qualquer conteúdo, fato que transforma a profissão e a atuação do profissional.

Nesse cenário, os alunos, futuros jornalistas, utilizam cada vez mais as possibilidades das TDIC em seu cotidiano dentro e fora da sala de aula, como comprova a pesquisa sobre o uso das tecnologias de informação e comunicação nas escolas brasileiras (TIC EDUCAÇÃO, 2018). De acordo com a pesquisa, 98\% dos alunos entrevistados, com 10 anos ou mais de idade, já acessaram a internet e, destes, $71 \%$ acessam mais de uma vez ao dia e $19 \%$ acessam pelo menos uma vez ao dia.

Nessa perspectiva, o aluno não deve mais ser considerado passivo, ele deve ser estimulado a participar, interagir e construir o seu conhecimento. Jenkins (2009) defende que não existe mais passividade nos usuários. Hoje todos participam, pois estamos inseridos no contexto da cultura participativa. Nesse paradigma e voltando os olhares para a educação, dispomos que os alunos estão diariamente conectados com as TDIC.

Santos (2010) ressalta que nos dias atuais a internet se apresenta como espaço de interação e que todos somos integrantes deste espaço. Neste trabalho consideramos interação consoante Pimentel (2017), que defende que a interação pode ser pensada como a reciprocidade entre dois ou mais sujeitos (intersubjetividade) de forma direta ou indireta, síncrona ou assíncrona, por meio de algum veículo de comunicação, como o computador, por exemplo. Ou seja, mesmo mediada por computador (PRIMO, 2007), as conversas, discussões e feedbacks que acontecem em ambientes virtuais são consideradas interações.

Porquanto, utilizar os recursos disponíveis na internet com orientações educacionais deve ter objetivo definido. Vidal e Mercado (2017) defendem que as TDIC proporcionam aos docentes conhecer novas propostas de educação. Por meio da internet, podemos ter acesso a 
diversos conteúdos. Para Imbernón (2016), a ideia de inserir tecnologia na universidade está relacionada ao alcance de melhorias e mudanças no processo de ensino-aprendizagem.

Atrelado a isso, Sunaga e Carvalho (2015) sugerem alguns recursos tecnológicos que podem ser utilizados pelos professores, entretanto a instituição de ensino ou os próprios estudantes, a depender do local de desenvolvimento da proposta pedagógica, devem possuir computadores com acesso a internet. Nesse quesito, carece ser realizado um trabalho de conscientização para que os alunos compreendam que o uso das TDIC em ambientes educacionais pauta-se em conteúdos acadêmicos, com foco educativo e objetivo de aprendizagem. Dentre os recursos tecnológicos, Sunaga e Carvalho (2015) sugerem o Ambiente Virtual de Aprendizagem (AVA), pois proporciona interação entre os alunos e possibilita disponibilizar materiais variados (vídeos, textos, planilhas, questionários).

A experiência aqui relatada utilizou como AVA e ferramenta pedagógica o Google Classroom como complementação às aulas presenciais na disciplina de oficina de produção audiovisual, no curso de Jornalismo da UFAL. A escolha foi pautada devido a uma das pesquisadoras interessar-se em realizar a experiência no curso de graduação em jornalismo. Ademais, o Google Classroom é uma plataforma simples, de certo modo intuitiva, gratuita, de fácil utilização e que permite o desenvolvimento de um espaço colaborativo online visando apoiar e complementar as aulas presenciais. A plataforma pode ser utilizada de qualquer dispositivo que tenha acesso à internet e possua um navegador, também há uma versão mobile disponível para baixar em Android e IOS, o que pressupõe a mobilidade, ou seja, o aluno pode acessar o AVA em qualquer espaço e tempo.

O artigo está subdividido da seguinte forma: primeiramente expomos o arcabouço teórico que fundamenta a prática desenvolvida no Google Classroom. Sequencialmente, abordamos o contexto da experiência, ou seja, como o projeto foi desenvolvido na disciplina de oficina de produção audiovisual. Em seguida descrevemos os procedimentos didáticos. Pontuamos, de forma detalhada, de que forma a experiência foi desenvolvida, quais atividades foram propostas e realizadas, as interações e os feedbacks, utilizando os prints das telas como forma de ilustração e exemplificação. Por fim, ressaltamos nossas considerações, avaliando o resultado da experiência e suas contribuições.

\section{Fundamentação Teórica}

Mesmo mediante a configuração social atual, em que as TDIC estão presentes no cotidiano, inseri-las no processo educativo requer planejamento, pois segundo Sancho (2006), as tecnologias podem se configurar como um recurso benéfico às propostas educativas visto que oportunizam aos docentes rever práticas e metodologias. Todavia a autora lembra que o uso de tecnologias demanda novos desafios e consciência pedagógica. Costa, Silva e Oliveira (2017) corroboram com Sancho na medida em que defendem que as tecnologias devem ser utilizadas com intencionalidade pedagógica. As autoras consideram que as TDIC oportunizam alternativas que não podem ser desprezadas na educação, posto que já estão imbricadas no contexto social. 
Uma dessas possibilidades proporcionadas pelas TDIC é o AVA que, de acordo com Santos (2010), está entre os mais utilizados nas práticas de educação online. Para Maciel (2018), o AVA permite a aprendizagem por meio da interação e mediação entre os atores do processo. "Esses ambientes são criados a partir das tecnologias digitais e utilizam-se da internet como meio de difusão e comunicação, oferecendo recursos de interação e comunicação" (MACIEL, 2018 , p. 31). Nessa perspectiva, o autor expõe que as TDIC e, consequentemente, a internet proporcionou o desenvolvimento do AVA, todavia a interação entre as pessoas é que pressupõe a aprendizagem.

Para Schlemmer (2010), o AVA propõe a administração e suporte aos processos de ensino e de aprendizagem baseados na internet. A autora ressalta que, por meio da internet, é possível compartilhar informações ultrapassando os limites de tempo e espaço. Sendo assim, os alunos constroem seu conhecimento em qualquer lugar e a qualquer hora.

Nesse sentido, Mattar (2011) pontua que os alunos se comunicam com o professor mais abertamente quando estão em ambientes virtuais e complementa que, por meio do ambiente, é possível apontar atividades, pesquisas e realizar intervenções. Para Churchill (2017), a educação na sociedade contemporânea exige que os professores transformem suas práticas pedagógicas e tornem-se designers de aprendizagem. O autor explica que os recursos digitais permitem, facilitam e medeiam atividades voltadas à aprendizagem.

Pensando a interação como pressuposto para a aprendizagem no AVA e considerando que interagir significa se comunicar, trocar informações, dialogar, ressaltamos Pimentel (2013), que entende que a palavra interação reflete a intersubjetividade, ou seja, a relação entre duas ou mais pessoas, seja de forma oral, escrita ou até mesmo gestual. Conforme Pimentel (2017), a interação deve ser pensada como a "ação recíproca entre dois ou mais atores, quando ocorre intersubjetividade numa relação direta ou indireta, mediatizada por algum veículo de comunicação" (PIMENTEL, 2017, p. 43). O autor denota que quando duas ou mais pessoas se comunicam em um AVA, por exemplo, seria interação, ou seja, trata-se de interação a troca de informações entre alunos e professor em um fórum de uma sala de aula virtual. Primo (2007) discute a interação como a ação, ou as mediações, que ocorrem entre os interagentes e pressupõe uma interação por meio da máquina, diferente da interação somente com a máquina, visto que o interagente modifica conteúdos.

Para que ocorra a interação no AVA, o papel desempenhado pelo professor corresponde desde o planejamento até a metodologia proposta por ele. Moran (2017) explica que as metodologias guiam os processos de ensino e aprendizagem. Nesse viés, o autor esclarece que as metodologias desenvolvidas "num mundo conectado e digital se expressam através de modelos de ensino híbridos, com muitas possíveis combinações" (MORAN, 2017, p 24), como é o caso de mesclar a aula presencial com momentos à distância. Filatro e Cavalcanti (2018) concordam com Moran (2017) e defendem que os alunos devem exercer papel ativo na sua aprendizagem, deixando de ser apenas receptores de informações e passando a construir seu conhecimento. 
Uma das formas de incentivar o aluno, especialmente no AVA, colocá-lo no centro do processo, considerando sua autonomia, é dando-lhe um rápido e cuidadoso feedback. Conforme Abreu-e-Lima e Alves (2018) a expressão feedback é bastante comum em espaços educacionais brasileiros, apesar de originalmente ser estrangeira, seu uso na educação se refere a ideia de fornecer ao aluno uma resposta acerca de uma atividade realizada. "É qualquer comunicação ou procedimento que vise informar ao educando/aprendiz da exatidão de uma resposta dada, em geral, a uma pergunta instrucional" (ABREU-E-LIMA; ALVES, 2018, p. 456), isto é, o feedback acontece quando o professor fornece informação ao aprendiz sobre como ele está evoluindo, ou não, em suas atividades.

Os autores ressaltam a importância de três pilares para o feedback na educação: o cuidado com a linguagem, com o conteúdo e com a constância, principalmente no que tange a educação a distância, pois o aluno não poderá visualizar a linguagem não-verbal do professor, dificultando assim o entendimento do contexto da mensagem. Zeferino, Domingues e Amaral (2007) defendem que o feedback incentiva os alunos e valoriza a aprendizagem, pois possibilita sintonizar o resultado real e o pretendido, sinalizando os comportamentos adequados e inspirando o aluno a reiterar seus estudos e, consequentemente, seus acertos.

Mediante essa conjuntura, a plataforma Google Classroom se configura como um AVA que pode ser utilizado para o desenvolvimento de metodologias ativas, colocando o aluno no centro do processo, promovendo a interação entre alunos e professor, além de conteúdos, ambiente e mídias (PIMENTEL, 2013), fornecendo feedback e assim proporcionando a construção do seu conhecimento.

\section{Contexto da Experiência Didática}

A experiência aqui relatada foi desenvolvida durante a disciplina de oficina de produção audiovisual. Trata-se de um trabalho qualitativo-descritivo, visto que descreve a vivência de uma das pesquisadoras com a utilização da plataforma Google Classroom no curso de Jornalismo da UFAL. A disciplina dispunha de carga horária de 120 horas em cada turma, totalizando 240 horas (turmas I e II), no quinto período noturno do curso de Jornalismo da UFAL. Ao todo, a turma contava com 46 alunos, sendo 29 alunos da turma I (2018.2) e 17 alunos da turma II (2019.1). A turma I era composta por graduandos, com idade entre 19 e 37 anos, que, em sua maioria, conciliavam trabalho e universidade. Já a turma II compunha-se de alunos mais jovens, com idade entre 17 e 24 anos de idade. Alguns já trabalhavam, mas grande parte apenas estagiava ou somente estudava.

Durante a disciplina trabalhamos conceitos e práticas acerca dos tipos de imagem e suas mesclas com as mídias visuais, atentando aos aspectos da linguagem e sua dimensão estética. Conhecemos as estruturas narrativas, os tipos de narradores e o ponto de vista de forma teórica e aplicada. Compreendemos a imagem fílmica e a sua relação com o espectador. Percebemos que o filme propicia a inserção de infinitos narradores diversificando o ponto de vista na narração fílmica. Ademais, realizamos atividades práticas de desenvolvimento e 
aplicação de roteiro/script à gravação e desta, à finalização a relação do espaço e o tempo no filme e ainda pré-produção, calendário de filmagem, gravação e montagem.

A disciplina propunha como objetivos: provocar no estudante um olhar específico para a produção audiovisual, capacitando-o tecnicamente a roteirizar, produzir, filmar e editar um curta-metragem, seja ele documental, experimental ou de ficção; entender e aplicar do roteiro/script à gravação e elaborar produtos audiovisuais em equipes.

A carga horária da disciplina era subdividida entre as quartas e quintas-feiras, da seguinte forma: quartas-feiras, das $20 \mathrm{~h} 50$ às $22 \mathrm{~h} 30$ e, nas quintas-feiras, das $18 \mathrm{~h}$ às $22 \mathrm{~h}$. Todavia, como a disciplina foi ofertada para o período noturno para as duas turmas (2018.2 e 2019.1), grande parte dos alunos, que dependiam de transporte público, permaneciam na aula da quarta-feira somente até às $21 \mathrm{~h}$, inviabilizando, desse modo, qualquer atividade proposta para a disciplina.

Nesse contexto, para não prejudicar os alunos e na tentativa de tornar as quartas-feiras mais produtivas, desenvolvemos, em consonância com as turmas, dois ambientes virtuais ${ }^{1}$, um para cada turma, na plataforma Google Classroom, no intuito de otimizar nossa experiência com a produção audiovisual.

A Figura 1 mostra a tela inicial do ambiente da plataforma Google Classroom da turma I.

Figura 1 - Tela inicial das salas de aula virtual no Google Classroom (turma I)

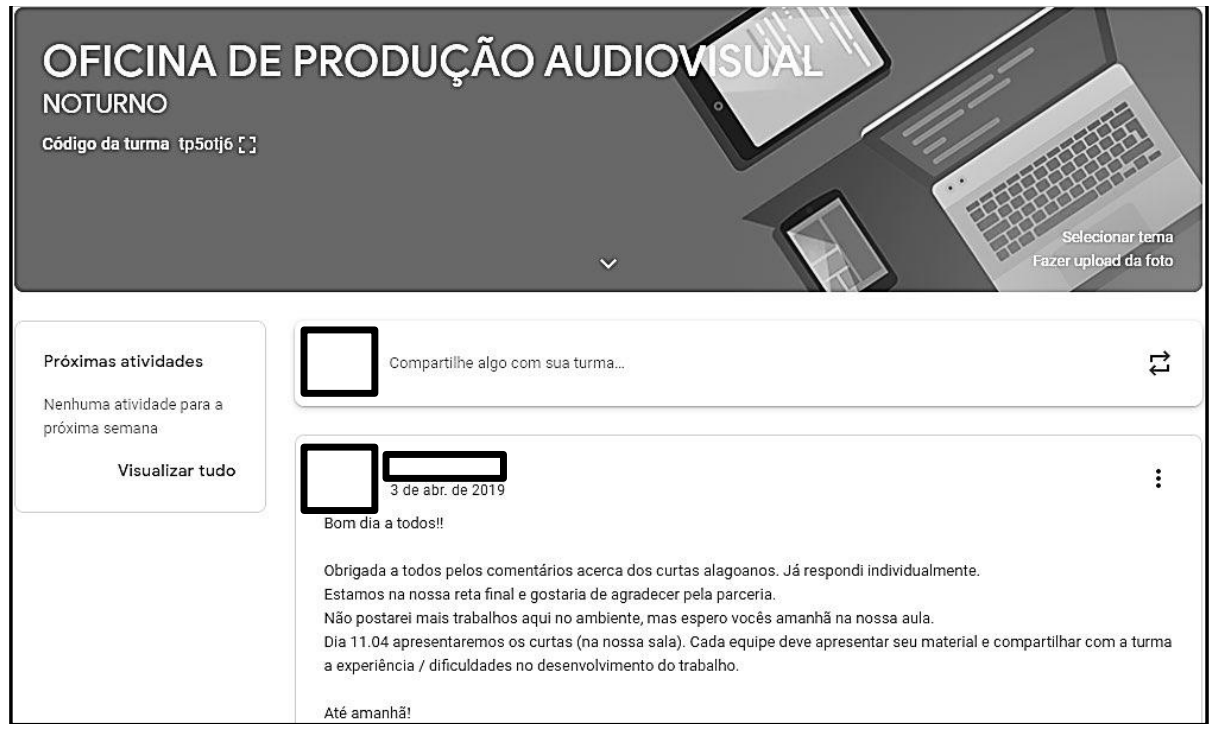

Fonte: Página do Google Classroom² (2019).

Enfatizamos que o ambiente virtual funcionava em substituição às aulas das quartas-feiras e em complementação às aulas presenciais que aconteciam durante às quintas-feiras na

\footnotetext{
${ }^{1}$ As salas de aula virtuais estão disponíveis nos endereços: https://classroom.google.com/u/0/c/MzA0Nzg4Mzg0OTVa (turma I, 2018.2) e https://classroom.google.com/u/0/c/MzY4ODkzMDgxNjha (turma II, 2019.1).

2 Disponível em: https://classroom.google.com/u/0/c/MzA0Nzg4Mzg0OTVa
} 
universidade. Assim, os alunos usariam o horário disponibilizado das quartas-feiras para interagir e realizar as atividades propostas na plataforma.

\section{Procedimentos Didáticos}

Com o objetivo de aflorar o interesse dos alunos, durante às quartas-feiras, na disciplina de oficina de produção audiovisual, aprofundar os conhecimentos acerca do cinema e do audiovisual e complementar as aulas presenciais que aconteciam às quintas-feiras no bloco de comunicação da universidade, a metodologia trabalhada no ambiente virtual baseou-se em discussão de textos através de fóruns/mural, produção e postagem de vídeos (feitos com o celular do próprio aluno), debates de temas polêmicos apresentados por meio de vídeo, elaboração de roteiro e, por fim, a produção de um curta-metragem com temática livre, escolhida pela equipe de até quatro integrantes, previamente determinada pelos alunos, com a supervisão dos pesquisadores. A atividade que envolveu a produção do curta-metragem não foi postada no ambiente virtual, mas apresentada em sala de aula, ou seja, os curtas foram exibidos em uma mostra de cinema previamente organizada pelos próprios alunos, inserindoos, desse modo, aos conteúdos e objetivos propostos pela ementa da disciplina e promovendo a interação entre as equipes.

A escolha do Google Classroom se deu devido a simplicidade no uso da plataforma, além de ser um espaço gratuito e que pode ser utilizado de maneira intuitiva até mesmo por meio do aplicativo no celular, pois possui uma versão mobile disponível para baixar em Android e IOS. Para fazer parte do ambiente virtual, os alunos recebem um código da turma, se cadastram através de e-mail e realizam login, caso o aluno não consiga se cadastrar por meio do código, o professor pode enviar um convite para participação. A partir de seu cadastro ou aceitação do convite, o aluno recebe notificação a cada postagem do professor no ambiente ou em cada interação em que seja mencionado o seu e-mail cadastrado.

O audiovisual foi discutido durante a disciplina de forma teórica e prática baseado em autores que trabalham com a temática (COMPARATO, 2000; MACHADO, 2007; METZ, 1977; RAMOS, 2008; SIMONARD, 2006; BARROS, 2010), dentre outros.

Iniciamos nosso trabalho no ambiente virtual da turma I com as boas-vindas para os participantes, apresentação do ambiente e normas de utilização no contexto da disciplina, lembrando que a participação nas atividades, discussões e interações seriam contabilizadas como presença e pontuação, de acordo com cada atividade. Em seguida, postamos a atividade 'Memória do Documentário Brasileiro que consistia em assistir a um vídeo e deixar suas impressões em formato de comentário no fórum, como mostra a Figura 2. 
Figura 2 - Postagens dos alunos no fórum Memória do Documentário Brasileiro (turma I)

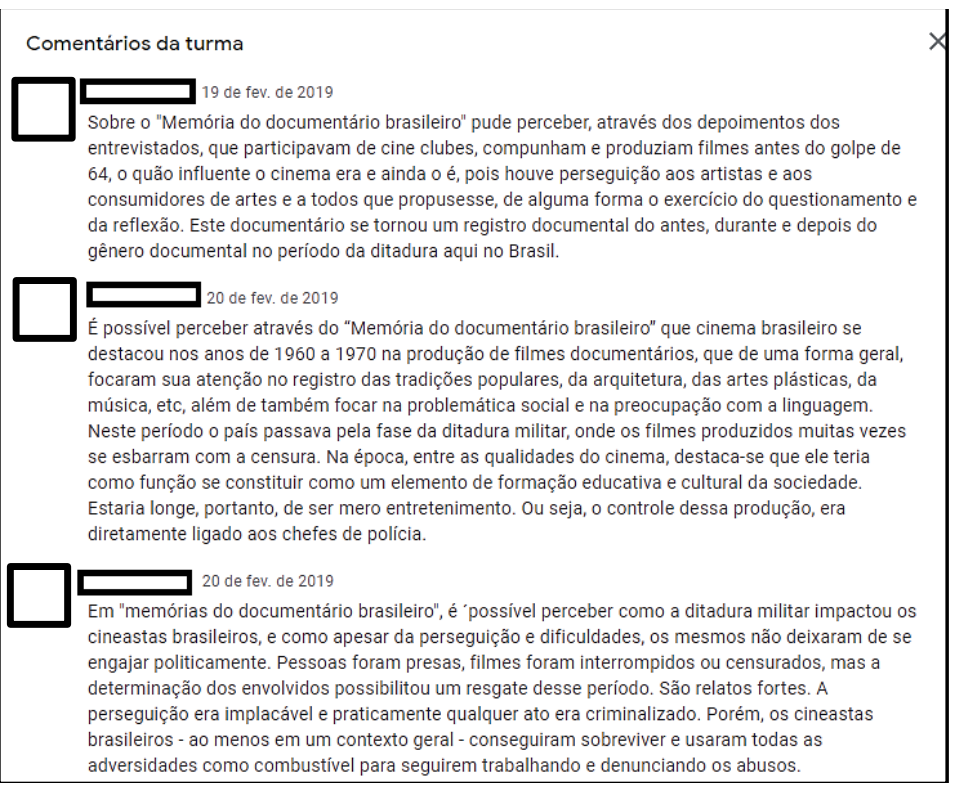

Fonte: Página do Google Classroom³ (2019).

A partir da Figura 2 é possível perceber mediante o conteúdo dos comentários que, de fato, os alunos assistiram atentamente ao vídeo proposto na atividade. Ademais ainda demonstraram conhecimentos prévios sobre o audiovisual produzido durante o período da ditadura militar no Brasil, agregando-os ao conhecimento adquirido através do vídeo, ou seja, construindo conhecimento por meio do comentário na plataforma Google Classroom.

Todavia, identificamos que devido à novidade na utilização da plataforma, 11 alunos, sendo 10 alunos da turma I (34,48\%) e 1 aluno da turma II (5,88\%), não conseguiram postar no fórum, como propunha a atividade, e realizaram o trabalho anexando seus comentários em formato de arquivo 'doc e 'pdf', como expõe a Figura 3.

Figura 3 - Exemplo de postagens dos alunos na atividade Memória do Documentário Brasileiro em formato de anexo

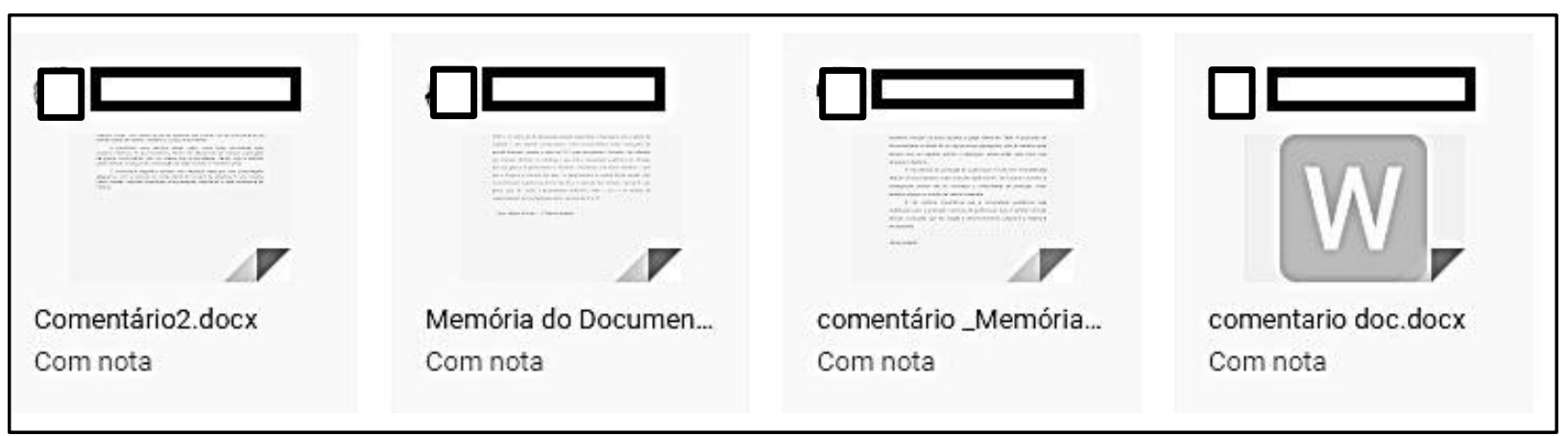

Fonte: Página do Google Classroom ${ }^{4}$ (2019).

\footnotetext{
${ }^{3}$ Disponível em: https://classroom.google.com/u/0/c/MzA0Nzg4Mzg00TVa/a/MzA0ODA3MDg0NjVa/details
} 
Percebe-se, nesse contexto, um cenário paradoxal, tendo em vista que na turma I apenas 4 alunos $(13,79 \%)$ tinham mais de 30 anos de idade e na turma II todos os alunos tinham menos de 30 anos de idade, ou seja, 42 alunos, o que equivale a 91,30\% no somatório das duas turmas, nasceram em meio às tecnologias digitais, a partir da década de 90 (PRENSKY, 2012). Desse modo, ao mesmo tempo em que possuem acesso a internet, como mostra a pesquisa TIC Domicílio 201855, são sábios digitais (PRENSKY, 2012), visto que utilizam a tecnologia em seu cotidiano para aguçar suas capacidades e estão continuamente conectados, tiveram dificuldade em utilizar os recursos da plataforma, porquanto eles não usavam o AVA em seu cotidiano.

Dentre as dificuldades destacamos a manipulação da plataforma e, consequentemente, a postagem de comentários, anexos e utilização do Google como AVA. Contudo, as problemáticas com a utilização da ferramenta Google Classroom foram superadas ao longo do desenvolvimento da disciplina, devido ao constante manuseio dos recursos oferecidos pelo ambiente. Os alunos aprenderam a utilizar a plataforma e passaram a postar suas atividades nas formas e locais corretos. Para tanto, a cada dúvida dos alunos estávamos à disposição para solucionar e prestar a devida assistência, principalmente no tocante ao manuseio do Google Classroom.

Na turma II, após as boas-vindas, pontuação das normas do AVA e demais orientações, foi proposta a primeira atividade, que consistiu na leitura de um texto sobre a 'Linguagem do Audiovisual e, em seguida, produção de um micro vídeo, de até três minutos, sobre qualquer temática. O vídeo deveria ser desenvolvido individualmente. As produções foram postadas no AVA e o feedback foi realizado de forma individual, visto que, conforme ressaltam Hattge, Ribas e Paulo (2014), em ambientes virtuais o feedback individual faz com que o aluno se sinta ouvido e parte do processo ensino-aprendizagem. A Figura 4 (p.9) mostra, mediante o vídeo postado por um dos alunos, a interação entre discente e docente, além do feedback recebido. Destacamos que o feedback acerca da confirmação de visualização do vídeo foi realizado no mesmo dia. Hattge, Ribas e Paulo (2014) defendem que um feedback rápido e eficaz é fundamental, pois instiga, fortalece e motiva o aluno. Os autores pontuam ainda a importância do feedback para o combate à evasão como também para a orientação do aluno quanto ao alcance de seu objetivo de aprendizagem.

\footnotetext{
${ }^{4}$ Disponível em: https://classroom.google.com/u/0/c/MzA0Nzg4Mzg0OTVa/a/MzA0ODA3MDg0NjVa/ submissions/bystatus/and-sort-first-name/all

${ }^{5}$ A pesquisa sobre o Uso das Tecnologias de Informação e Comunicação nos Domicílios Brasileiros (TIC Domicílio 2018), realizada pelo Centro Regional de Estudos para o Desenvolvimento da Sociedade da Informação (Cetic) ressalta que 126,9 milhões de indivíduos com dez anos ou mais estão conectados à rede, o que representa $70 \%$ da proporção de usuários de internet no País.
} 
Figura 4 - Exemplo de feedback e interação na postagem do aluno

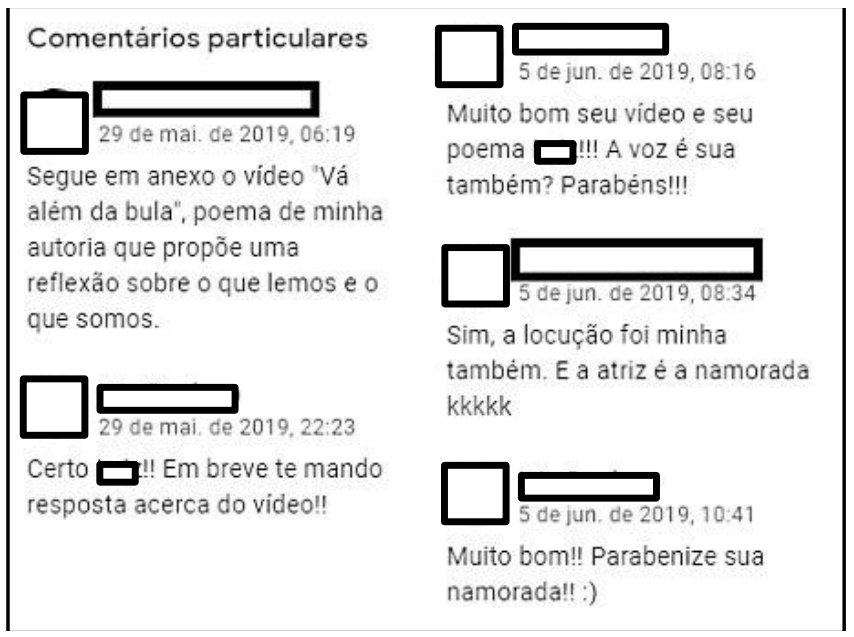

Fonte: Página do Google Classroom ${ }^{6}$ (2019).

Além de atividades e discussão, avisos sobre prazos para entrega de trabalhos, aulas suspensas e atividades extraclasse também foram postados. A cada postagem o aluno recebia uma notificação no e-mail cadastrado ou no aplicativo, caso o tivesse instalado em seu celular. A segunda proposta para a turma I consistiu na leitura de um artigo sobre o cineasta alagoano Celso Brandão e posterior postagem de comentário no fórum. Nessa atividade foi ponderada a proposta de interação com os colegas por meio dos comentários. Ao todo, 14 alunos realizaram a atividade, sendo 8 comentários postados diretamente no AVA e 7 através de documento anexo. Destacamos que os 7 alunos que realizaram as postagens por meio de documento anexo, apresentaram dificuldade em utilizar a plataforma também na primeira atividade. Mais uma vez, os feedbacks foram individualizados.

Já na turma II, a segunda atividade foi diferente devido ao perfil mais jovem da turma, na qual grande parte dos alunos somente estudava e dispunha de um tempo maior para a realização de atividades que demandavam mais detalhes, como no caso da escrita de um roteiro. Sendo assim, nesta proposta, os alunos deveriam assistir a um curta 'Cores e Botas e produzir um esqueleto de roteiro desse curta, ou seja, a ideia foi inverter o trabalho onde normalmente a escrita do roteiro precede à produção do filme. Para Leal (2005), o planejamento, do ângulo educacional, expõe, além das intenções do professor, a meta que o docente busca atingir. Por esse motivo, as atividades planejadas e desenvolvidas com cada turma foram díspares, todavia pautadas no mesmo conteúdo.

Com o desenvolvimento da metodologia da disciplina na sala de aula presencial, notamos que a turma I se interessava mais por atividades que envolvessem textos e elaboração de comentários, a turma II, no entanto, apreciava, em sua maioria, atividades práticas com feedback rápido. Nesse sentido, foi pensada a terceira proposta para as duas turmas. Na turma

6Disponível em: https://classroom.google.com/u/0/g/tg/MzY4ODkzMDgxNjha/MzY4OTQyMDEwODRa\#u= MzY5MzU0MTQ4Mjda\&t=f 
I, a atividade consistiu na leitura de um texto, vídeo e elaboração de comentário sobre a fase moderna do cinema em Alagoas, marcada pela realização do segundo e último longa alagoano' A Volta pela Estrada da Violência', de 1971. Na turma II, a atividade consistiu em um quiz de perguntas e respostas sobre a 'História do Cinema Documental', conteúdo desenvolvido na sala de aula presencial, como mostra o texto disposto na descrição da atividade na Figura 5. o questionário foi elaborado utilizando o formulário do Google e o feedback era emitido instantaneamente por meio respostas elaboradas anteriormente pela docente.

Figura 5 - Capa do quiz (perguntas e respostas) sobre a História do Cinema Documental

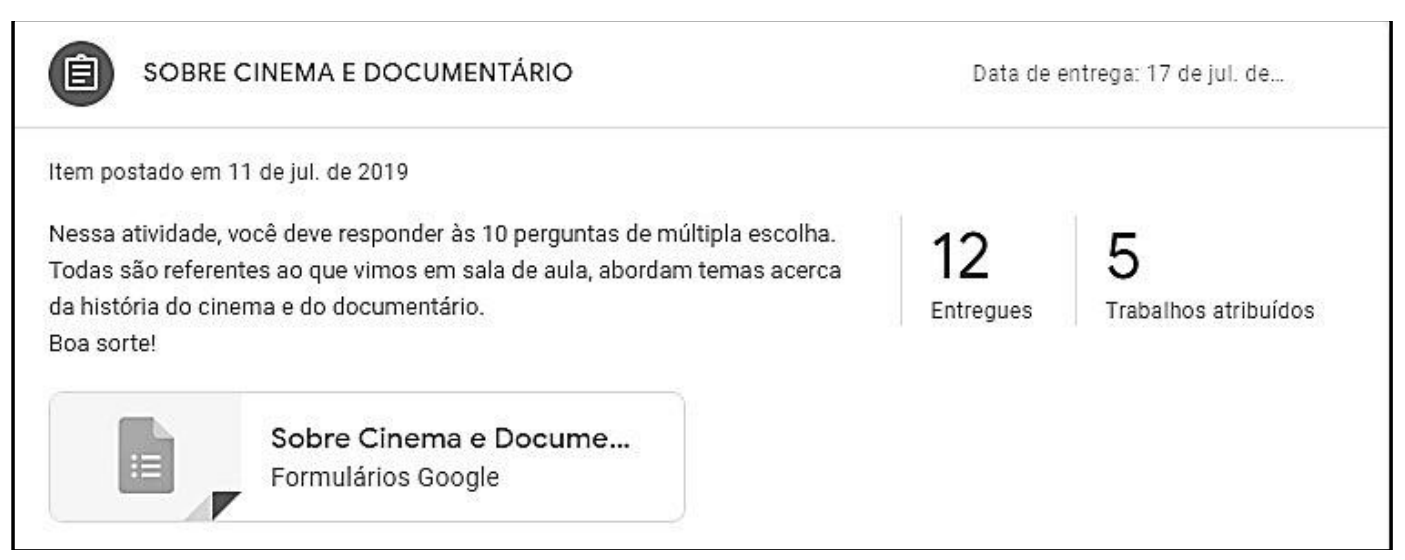

Fonte: Página do Google Classroom ${ }^{7}$ (2019).

Com o cinema alagoano sendo pautado durante os momentos presenciais na turma I, convidamos um jovem cineasta alagoano para uma 'mesa redonda que aconteceria presencialmente. Para tanto, realizamos uma discussão acerca de algumas produções do nosso convidado no ambiente da plataforma. Com o objetivo de compreender a obra e o perfil do cineasta, postamos três curtas ${ }^{8}$ com diferentes abordagens para que os alunos assistissem e comentassem no fórum para posterior debate na mesa redonda presencial.

Os momentos presenciais da turma II também pautavam as produções audiovisuais alagoanas e o cinema documentário brasileiro, por esse motivo foram pensadas mais duas atividades com leitura de textos, vídeos e postagem de comentários no fórum, visto que esta turma ainda não havia realizado atividades nesse sentido.

Salientamos a percepção de que os debates nos momentos presenciais se tornaram mais subsidiados e entusiasmados, uma vez que os estudantes realizavam as leituras, desenvolviam as atividades propostas e assistiam aos vídeos disponíveis no AVA, se interessando, discutindo e participando mais ativamente das aulas.

Ao final da disciplina foi solicitada para as duas turmas a produção de um curta-metragem com temática de livre escolha para a equipe. Na turma I, foram produzidos seis vídeos, sendo

\footnotetext{
7 Disponível em: https://classroom.google.com/u/0/w/MzY4ODkzMDgxNjha/t/all

${ }^{8} \mathrm{O}$ material está disponível em: https://classroom.google.com/u/0/c/MzA0Nzg4Mzg0OTVa/m/MzEyMzE5 MDMXODRa/details
} 
quatro documentários ('Entre o mar e o asfalto', 'Nilda Rosa', 'O Nagô e o tempo e 'Um olhar para a acessibilidade: a exclusão na era da inclusão') e duas ficções ('Noite de terror e 'O caderno'). Na turma II, foram feitos cinco vídeos, sendo três documentários ('Nallunna', 'Nem tudo é passageiro e 'Ainda resiste hip hop') e duas fiç̧̃es ('O silêncio dos vestígios e 'Jornal'). As produções foram apresentadas presencialmente, em sala de aula.

Os curtas produzidos pelas turmas I e II mostraram o engajamento das equipes e a preocupação dos alunos em desenvolver um material de qualidade, mesmo sem apoio financeiro, pois todos os recursos para a produção do vídeo foram dos próprios estudantes. As narrativas escolhidas para os curtas evidenciaram a empatia dos discentes com as causas sociais, ressaltando, nesses alunos, o aspecto crítico, o olhar, e o papel social do jornalista. Ademais, a experiência de produção também destacou a importância da pesquisa, da escrita e do trabalho em equipe para a consolidação de uma peça audiovisual.

\section{Considerações Finais}

A experiência aqui relatada abordou a utilização da plataforma Google Classroom como AVA na disciplina de oficina de produção audiovisual, ofertada nas turmas 2018.2 e 2019.1, no turno noturno do curso de graduação em Jornalismo da UFAL.

Ressaltamos que os graduandos das turmas I e II têm acesso à tecnologia e, em sua maioria, utilizam as possibilidades oferecidas pelas TDIC em sua rotina, inclusive na sala da aula. Desse modo, a experiência fluiu de forma natural no que tange ao uso da internet, do computador e/ou da tecnologia móvel pelos alunos, ou seja, os discentes acessam a internet e manuseiam o hardware (computador, smartphone) com certa facilidade e intimidade.

Todavia, apesar de se tratar de turmas com acesso e habilidades para o uso das tecnologias, a utilização da plataforma Google Classroom foi pautada por algumas dificuldades, pois mesmo diante do fato de o Google ser conhecido e utilizado mundialmente, os alunos não possuíam contato com o AVA. Outrossim, também ressaltamos que as dificuldades dos alunos com relação à manipulação da plataforma e postagem de comentários e materiais anexos foram apenas no início da utilização, porquanto com a constante manipulação dos recursos, os estudantes aprenderam a utilizar o ambiente sem maiores problemáticas ou dificuldades.

Durante as interações no AVA, apresentamos textos, vídeos, questionários e abordamos conteúdos relativos ao audiovisual no mundo. Enfatizamos aspectos do cinema no Brasil e, com maior ênfase, em Alagoas. Ao final da disciplina, os alunos desenvolveram, em equipes, curtasmetragens que foram exibidos em mostras de cinema realizadas na universidade e organizadas pelos próprios alunos.

Avaliamos a aprendizagem dos alunos mediante o desempenho individual nas discussões em sala de aula, também por meio das postagens no AVA acerca do conteúdo trabalhado e ainda através do acompanhamento do processo de roteirização e produção dos curtas.

A experiência permitiu a complementação das aulas presenciais das quintas-feiras, que estavam deveras prejudicadas devido ao horário de entrada do transporte coletivo na 
universidade, aprofundou os conhecimentos acerca do cinema e audiovisual, além de otimizar o tempo e o interesse dos alunos nas aulas, alcançando assim os objetivos propostos. Ademais, os alunos participaram de forma efetiva nos momentos presenciais e a sala de aula se tornou palco para debates acalorados, mas subsidiados, posto as atividades realizadas no AVA. Nesse sentido, consideramos que o uso da plataforma para essa proposta e inserida nesta didática de aula foi efetivo e contribuiu para a maior participação e interesse dos alunos pela disciplina.

\section{Referências}

ABREU-E-LIMA, Denise Martins; ALVES, Mario Luiz Nunes. Modelos de feedback. In: MILL, Daniel (org.). Dicionário crítico de educação e tecnologias e de educação à distância. Campinas: Papirus, 2018, p. 456- 458.

CHURCHILL, Daniel. Educational Reforms, Learning-Centred Education and Digital Resources for Learning. In: CHURCHILL, Daniel. Digital Resources for Learning. Singapore: Springer, 2017.

COSTA, Cleide Jane de Sá Araújo; SILVA, Carla Glycia Santos da Silva; OLIVEIRA, Josefa Kelly Cavalcante de. Projeto um computador por aluno (PROUCA): incorporação das TDIC na educação básica. In: COSTA, Cleide Jane de Sá Araújo; PINTO, Anamelea de Campos (orgs.). Tecnologias Digitais da Informação e Comunicação. Maceió: Edufal, 2017, p. 61 - 72.

HATTGE, Andrea Adriani Gosenheimer; RIBAS, Cíntia Cargnin Cavalheiro; PAULO, Andrea Barbosa Delfini. A importância do feedback do tutor on-line no ensino a distância. ENSAIOS PEDAGóGICOS Revista Eletrônica do Curso de Pedagogia das Faculdades-OPET, 2014.

IMBERNÓN, Francisco. Mejorar la enseñanza y el aprendizaje em la universidad. São Paulo: Edições Hipótese, 2016.

JENKINS, Henry. Cultura da Convergência; tradução Susana Alexandria. São Paulo: Aleph, 2009.

LEAL, Regina Barros. Planejamento de ensino: peculiaridades significativas. Revista Iberoamericana de Educación, v. 37, n. 3, p. 1-6, 2005. Disponível em: file://C:/Users/55829/AppData/Local/Packages /Microsoft.MicrosoftEdge_8wekyb3d8bbwe/TempState/Downloads/Leal_Planejamento_de_Ensino\%20(1). pdf. Acesso em: 03 fev. 2020.

LÉVY, Pierre. Cibercultura. Tradução de Carlos Irineu da Costa. São Paulo: Editora 34, 1999.

MACHADO, Elias. O ciberespaço como fonte para os jornalistas. 2003. Disponível em: http://www.bocc.ubi.pt/ boccmirror/pag/machado-elias-ciberespaco-jornalistas.pdf. Acesso em: 11 mar. 2020.

MACIEL, Cristiano. Ambientes virtuais de aprendizagem. In: MILL, Daniel (org.). Dicionário crítico de educação e tecnologias e de educação à distância. Campinas: Papirus, 2018, p. 31- 33.

MATTAR, João. Guia de educação a distância. São Paulo: Cengage Learning: Portal Educação, 2011.

TIC DOMICÍLIO. Pesquisa sobre o uso das tecnologias de informação e comunicação da população brasileira: TIC Domicílio 2018. São Paulo: Comitê Gestor da Internet no Brasil, 2019. CETIC. Disponível em: https://www.cetic.br/media/docs/publicacoes/2/12225320191028-tic_dom_2018_livro_eletronico.pdf. Acesso em: 10 mar. 2020.

TIC EDUCAÇÃO. Pesquisa sobre o uso das tecnologias de informação e comunicação da população brasileira: TIC Educação 2018. São Paulo: Comitê Gestor da Internet no Brasil, 2019. CETIC. Disponível em: https://cetic.br/tics/educacao/2018/escolas-urbanas-alunos/B3/. Acesso em: 10 mar. 2020.

PIMENTEL, Fernando Silvio Cavalcante. Interação on-line: um desafio da tutoria. Maceió: Edufal, 2013.

PIMENTEL, Fernando Silvio Cavalcante. A aprendizagem das crianças na cultura digital. $2^{a}$ ed. rev. e ampl. Maceió: Edufal, 2017.

PRENSKY, Marc. Homo sapiens digital: dos imigrantes e nativos digitais à sabedoria digital. In: APARICI, Roberto. Conectados no ciberespaço. São Paulo: Paulinas, 2012, p. 101-116. 
PRIMO, Alex. Interação mediada por computador: comunicação, cibercultura, cognição. Porto Alegre: Sulina, 2007.

SANCHO, Juana María et al. De tecnologias da informação e comunicação a recursos educativos. In: SANCHO, Juana Maria; HERNÁNDEZ, Fernando. Tecnologias para transformar a educação. Porto Alegre: Artmed, 2006, p. 15-41.

SANTOS, Alberto Faustino Mesquita. Plataformas robustas e adaptáveis para a gestão e massificação de conteúdos dinâmicos: utilização em ambientes educacionais contribuindo para o sucesso educativo no ensino secundário em Portugal. 2010. Dissertação (Mestrado) - Comércio Eletrónico e Internet, Universidade Aberta, Lisboa. 2010.

SANTOS, Edméa. Educação online para além da EAD: um fenômeno da cibercultura. In: SILVA, Marco et. al (org.). Educação online: cenário, formação e questões didático-metodológicos. Rio de Janeiro: wak, 2010, p. 29-48.

SCHLEMMER, Eliane. Dos ambientes Virtuais de Aprendizagem aos Espaços de Convivência Digital Virtuais - Ecodis: o que se mantêm? O que se modificou? . In: VALENTINI, Carla Beatris; SOARES, Eliana Maria do Sacramento (orgs.). Aprendizagem em ambientes virtuais: compartilhando ideias e construindo cenários. Caxias do Sul, RS: Educs, 2010, p. 145 - 191.

SILVA, Fernando Firmino da. Jornalismo reconfigurado: tecnologias móveis e conexões sem fio na reportagem de campo. 2008. Disponível em:

https://www.researchgate.net/profile/Fernando_Silva58/publication/228533916_Jornalismo_Reconfigurado _tecnologias_moveis_e_conexoes_sem_fio_na_reportagem_de_campo/links/55a13a8308aea815dffbfdba/J ornalismo-Reconfigurado-tecnologias-moveis-e-conexoes-sem-fio-na-reportagem-de-campo.pdf. Acesso em: 10 mar. 2020.

SUNAGA, Alexandro; CARVALHO, Camila Sanches. As tecnologias digitais no ensino híbrido. In: BACICH, Lilian; TANZI NETO, Adolfo; TREVISANI, Fernando de Mello. (orgs.) Ensino Híbrido: Personalização e Tecnologia na Educação. Porto Alegre: Penso, 2015, p. 141-154.

VIDAL, Odaléa Feitosa; MERCADO, Luis Paulo Leopoldo. Integração das tecnologias digitais da informação e comunicação em práticas pedagógicas inovadoras no ensino superior. In: COSTA, Cleide Jane de Sá Araújo; PIMENTEL, Fernando Silvio Cavalcante (orgs.). Educação e tecnologias digitais da informação e comunicação: inovações e experimentos. Maceió: Edufal, 2017, p.47-57.

ZEFERINO, Angélica Maria Bicudo; DOMINGUES, Rosângela Curvo Leite; AMARAL, Eliana. Feedback como estratégia de aprendizado no ensino médico. Revista Brasileira de Educação Médica, v. 31, n. 2, 2007, p. 176-179. Disponível em: http://www.scielo.br/scielo.php?pid=S010055022007000200009\&script=sci_arttext\&tIng=pt. Acesso em: 04 fev. 2020.

Recebido em abril de 2020.

Aprovado para publicação em dezembro de 2020.

\section{Isis Nalba Albuquerque Cardoso}

Programa de Pós-Graduação em Educação- Universidade Federal de Alagoas - UFAL, Brasil, isiscardoso@gmail.com

\section{Cleide Jane de Sá Araújo Costa}

Programa de Pós-Graduação em Educação- Universidade Federal de Alagoas - UFAL, Brasil, cleidejanesa@gmail.com

\section{Fernando Silvio Cavalcante Pimentel}

Programa de Pós-Graduação em Educação- Universidade Federal de Alagoas - UFAL, Brasil, prof.fernandoscp@gmail.com 